\title{
DILATASI WAKTU
}

\author{
Anisah RM, Silvia Wulandari, dan Nana \\ Pendidikan Fisika FKIP Universitas Siliwangi \\ Tasikmalaya Jawa Barat Indonesia 46115 \\ rmanisahanisa24@gmail.com \\ wulandarisilvia88@gmail.com \\ nana@unsil.ac.id
}

\begin{abstract}
Abstrak
Eksperimen yang kami lakukan yaitu bertujuan untuk memahami konsep mengenai dilatasi waktu, menentukan nilai dilatasi waktu, dan membandingkan nilai dilatasi waktu. Metode yang kami gunakan yaitu metode eksperimen dengan memanfaatkan penerapan aplikasi virtual yang mudah diakses di internet. Percobaan ini dapat dilakukan dengan merubah-rubah nilai dari kecepatan $(v)$ sehingga secara otomatis kita mendapatkan data nilai dari dilatasi waktu. Setelah kita dapatkan data nilai dilatasi waktu secara perhitungan aplikasi virtual, kita juga melakukan perhitungan secara manual kemudian kita bandingkan kedua nilai dilatasi waktu tersebut. Sehingga dapat kami simpulkan dari eksperimen ini yaitu nilai dilatasi waktu secara perhitungan aplikasi virtual maupun perhitungan manual didapatkan hasil yang ekuivalen atau hampir sama sehingga bersesuaian dengan konsep dilatasi waktu dimana jam akan berjalan lebih cepat menurut pengamat yang diam relatif terhadap jam, sedangkan bagi pengamat yang tidak diam relatif terhadap jam maka jam akan bergerak lebih lambat.
\end{abstract}

Kata Kunci: dilatasi waktu, nilai, aplikasi virtual, eksperimen, dan perhitungan.

\section{PENDAHULUAN}

Dalam dunia pendidikan, salah satu mata pelajaran yang paling ditakuti dan kurang diminati oleh peserta didik yaitu mata pelajaran Fisika. Peserta didik menganggap mempelajari Fisika sangat membosankan dan sulit dipahami karena terlalu banyak konsep dan rumus yang digunakan dalam perhitungannya.

Salah satu materi yang sulit dipahami dalam mata pelajaran Fisika yaitu materi dilatasi waktu. Dilatasi waktu merupakan salah satu efek dari adanya relativitas khusus Einstein. Dimana dalam memahami konsep dilatasi waktu ini memang cukup sulit. Selain itu, dalam memberikan contoh aplikasi langsung dari dilatasi waktu dalam kehidupan sehari-hari pun cukup sulit, sehingga kami berinisiatif memberikan pemahaman konsep dilatasi waktu melalui metode eksperimen.

METODE

Metode yang kami gunakan yaitu metode eksperimen. Metode eksperimen ini memanfaatkan aplikasi virtual yang dikembangkan oleh Atribusi Creative Commons Atribusi-NonCommercialShareAlike $\quad 4.0 \quad$ Lisensi 
Internasional dengan alamat URL https://www.walter-

fendt.de/html5/phen/timedilation_e n.htm.

\section{HASIL DAN PEMBAHASAN}

Kita ketahui bahwa dilatasi waktu terlahir dari adanya konsep teori relativitas khusus Einstein. Kita gunakan postulat relativitas khusus untuk menyelidiki bagaimana gerak relatif mempengaruhi selang waktu.

Sebuah lonceng yang bergerak terhadap pengamat kelihatannya berdetak lebih lambat daripada jika lonceng itu diam terhadapnya. Ini berarti, jika seorang pengamat dalam suatu roket mendapatkan selang waktu antara dua kejadian dalam roket itu $t_{0}$, orang dibumi mendapatkan bahwa selang waktu tersebut lebih panjang, yaitu $t$.

Kuantitas $t_{0} \quad$ yang ditentukan oleh kejadian yang terdapat pada tempat yang sama dalam kerangka acuan pengamatnya disebut waktu proper antara kejadian itu. Bila diamati dari bumi, kejadian yang menandai permukaan dan akhir selang waktu itu terjadi pada tempat yang berbeda, dan mengakibatkan selang waktunya kelihatan lebih panjang dari waktu proper. Efek ini disebut pemuaian waktu atau dilatasi waktu.

Dalam teorinya Einstein beranggapan bahwa tidak ada benda bergerak atau diam yang absolut atau mutlak. Semuanya bersifat relatif tergantung kerangka acuan yang dipakai.
Selain itu, menurut postulat kedua Einstein menyatakan bahwa kepesatan cahaya dalam ruang hampa sama besar untuk semua pengamat, tidak bergantung dari keadaan gerak pengamat itu.

Jadi, dapat kita ketahui bahwa hanya cahaya yang memiliki kecepatan konstan atau mutlak terhadap semua kerangka acuan. Dari manapun cahaya diamati entah dari atas pesawat, dari atas mobil, atau oleh orang yang diam sekalipun kecepatannya akan tetap $3 \times 10^{8} \mathrm{~m} / \mathrm{s}$.

Setelah kita ketahui bahwa nilai kecepatan cahaya selalu konstan, maka ketika ada variabel lain yang mempengaruhi seperti variabel $v$ maka ia akan berusaha untuk mengkonstankan diri dengan mempengaruhi variabel lain yaitu $t$, dan ingat variabel kecepatan sifatnya kontinyu dan selalu melibatkan waktu $(t)$.

Akhirnya kita ketahui bahwa dilatasi waktu adalah konsekuensi dari teori relativitas khusus di mana dua pengamat yang bergerak relatif terhadap satu sama lain akan mengamati bahwa jam pengamat lain berdetak lebih lambat dari jamnya. Peristiwa ini bukanlah akibat dari kesalahan jam atau faktor teknis lainnya, tetapi merupakan sifat dasar dari ruangwaktu yang dijelaskan dalam teori relativitas.

Dengan kata lain bahwa jam akan berjalan lebih cepat menurut pengamat yang diam relatif terhadap jam, sedangkan bagi pengamat yang tidak diam 
relatif terhadap jam maka jam akan bergerak lebih lambat.

Secara kuantitatif, jika menurut pengamat A jamnya menyatakan selang waktu sebesar $t^{\prime}$, maka selang waktu ini akan teramati oleh pengamat $\mathrm{B}$ sebesar $t$ dengan hubungan matematis yang dapat dinyatakan dalam persamaan berikut:

$$
t^{\prime}=\frac{t^{\prime}}{\sqrt{1-\frac{v^{2}}{c^{2}}}}
$$

Dengan

$t=$ selang waktu yang terukur oleh pengukur yang bergerak relatif (di luar sistem)

$t^{\prime}=$ selang waktu yang terukur oleh pengukur yang diam (dalam satu sistem)

$v=$ kelajuan relatif pengukur $(\mathrm{m} / \mathrm{s})$

$c$ = kecepatan cahaya dalam ruang hampa $\left(3 \times 10^{8} \mathrm{~m} / \mathrm{s}\right)$

Dalam kejadian nyata kasus dilatasi waktu pernah terjadi, yaitu saudara kembar yang memiliki usia rentang waktu yang jauh berbeda akibat salah satu dari mereka melakukan perjalanan keluar angkasa selama kurun waktu beberapa tahun. Kejadian nyata pada kasus dilatasi waktu ini biasa disebut dengan paradoks kembar.

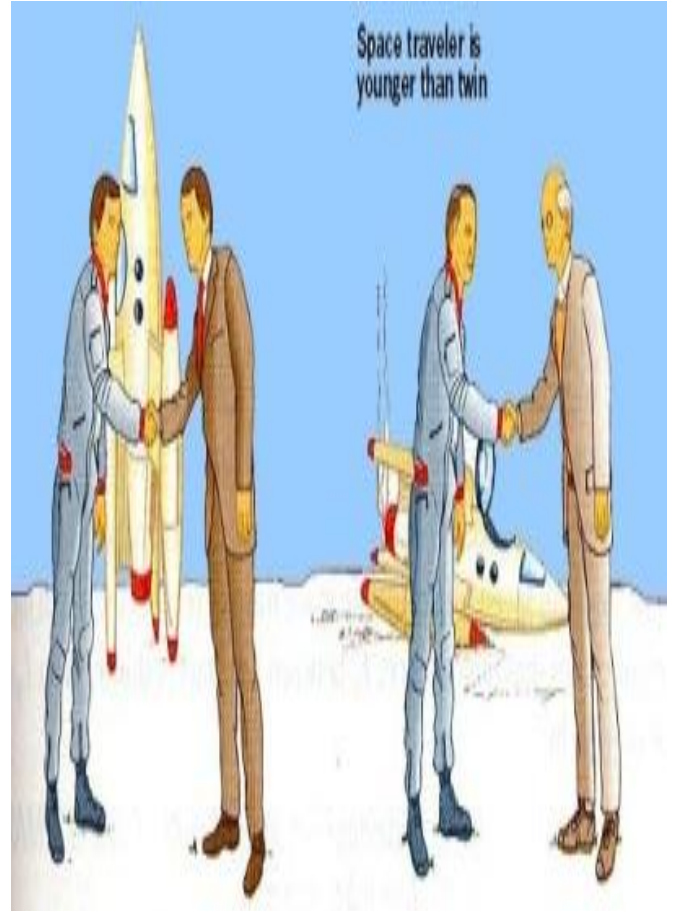

Gambar 1. Paradoks Kembar

Adapun alat dan bahan yang digunakan dalam eksperimen ini yaitu handphone atau laptop, kertas, dan bolpoint. Selain itu, adapun langkah kerja dalam eksperimen ini yaitu sebagai berikut (1) siapkan handphone atau laptop, (2) aktifkan data seluler sehingga mampu mengakses URL berikut https://www.walterfendt.de/html5/phen/timedilation_e $\underline{\text { n.htm, }}$ (3) aatur nilai dari kecepatan $(v)$ menggunakan menu increase speed untuk menambah kecepatan dan menu reduce speed untuk menurunkan kecepatan, (4) klik menu start untuk menjalankan virtual dan lihat nilai untuk dilatasi waktu pada menu flying time earth system ( $t)$ dan flying time spaceship system $\left(t^{\prime}\right)$, (5) pilih menu reset untuk memulai kembali virtual tersebut, (6) ulangi langkahlangkah tersebut sebanyak 10 kali percobaan dengan mengatur menu speed $(v)$ yang berbeda-beda dan 
tuliskan hasil percobaan ke dalam tabel data percobaan.

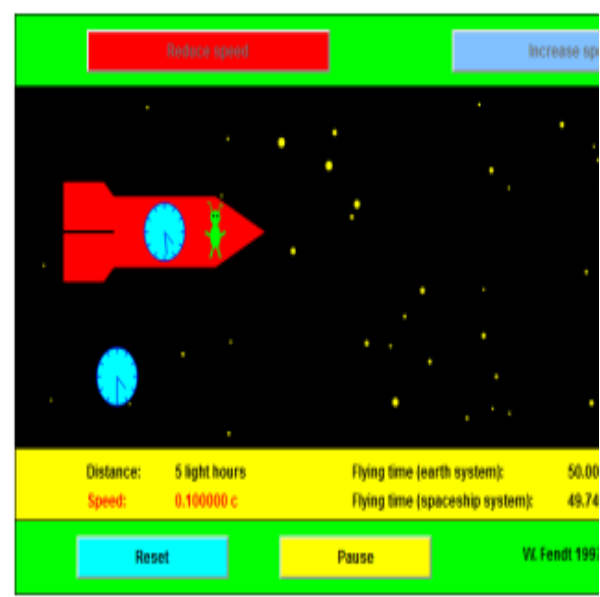

Gambar 2. Tampilan Virtual Dilatasi Waktu

Berikut tabel data hasil perhitungan secara aplikasi virtual dan perhitungan secara manual.

Tabel 1. Data Nilai Dilatasi Waktu secara Perhitungan Aplikasi Virtual

\begin{tabular}{|c|c|c|c|c|}
\hline No & $\begin{array}{c}\text { Kec } \\
\text { epat } \\
\text { an } \\
(\mathbf{v})\end{array}$ & $\begin{array}{c}\text { Kece } \\
\text { patan } \\
\text { Caha } \\
\text { ya (c) }\end{array}$ & $\begin{array}{c}\text { Wakt } \\
\text { u di } \\
\text { Bumi } \\
(\mathbf{t})\end{array}$ & $\begin{array}{c}\text { Wakt } \\
\text { u di } \\
\text { Luar } \\
\text { Angk } \\
\text { asa } \\
\left(\boldsymbol{t}^{\prime}\right)\end{array}$ \\
\hline \multirow{3}{*}{1} & 0.10 & $3 \mathrm{x}$ & 50.00 & 49.74 \\
& 0000 & $10^{8}$ & 0000 & 9372 \\
$\mathrm{c}$ & $\mathrm{m} / \mathrm{s}$ & $\mathrm{Jam}$ & $\mathrm{Jam}$ \\
\hline \multirow{3}{*}{2} & 0.20 & $3 \mathrm{x}$ & 25.00 & 24.49 \\
& 0000 & $10^{8}$ & 0000 & 4897 \\
& $\mathrm{c}$ & $\mathrm{m} / \mathrm{s}$ & $\mathrm{Jam}$ & $\mathrm{Jam}$ \\
\hline \multirow{3}{*}{3} & 0.30 & $3 \mathrm{x}$ & 16.66 & 15.89 \\
& 0000 & $10^{8}$ & 6667 & 8987 \\
& $\mathrm{c}$ & $\mathrm{m} / \mathrm{s}$ & $\mathrm{Jam}$ & $\mathrm{Jam}$ \\
\hline \multirow{3}{*}{4} & 0.40 & $3 \mathrm{x}$ & 12.50 & 11.45 \\
& 0000 & $10^{8}$ & 0000 & 6439 \\
& $\mathrm{c}$ & $\mathrm{m} / \mathrm{s}$ & $\mathrm{Jam}$ & $\mathrm{Jam}$ \\
\hline \multirow{2}{*}{5} & 0.50 & $3 \mathrm{x}$ & 10.00 & 8.660 \\
& 0000 & $10^{8}$ & 000 & 254 \\
& $\mathrm{c}$ & $\mathrm{m} / \mathrm{s}$ & $\mathrm{Jam}$ & $\mathrm{Jam}$ \\
\hline 6 & 0.60 & $3 \mathrm{x}$ & 8.333 & 6.666 \\
\hline
\end{tabular}

\begin{tabular}{|c|c|c|c|c|}
\hline & $\begin{array}{c}0000 \\
\mathrm{c}\end{array}$ & $\begin{array}{c}10^{8} \\
\mathrm{~m} / \mathrm{s}\end{array}$ & $\begin{array}{c}333 \\
\text { Jam }\end{array}$ & $\begin{array}{c}667 \\
\text { Jam }\end{array}$ \\
\hline \multirow{4}{*}{7} & 0.70 & $3 \mathrm{x}$ & 7.142 & 5.101 \\
& 0000 & $10^{8}$ & 857 & 020 \\
$\mathrm{c}$ & $\mathrm{m} / \mathrm{s}$ & $\mathrm{Jam}$ & $\mathrm{Jam}$ \\
\hline \multirow{4}{*}{8} & 0.80 & $3 \mathrm{x}$ & 6.250 & 3.750 \\
& 0000 & $10^{8}$ & 000 & 000 \\
& $\mathrm{c}$ & $\mathrm{m} / \mathrm{s}$ & $\mathrm{Jam}$ & $\mathrm{Jam}$ \\
\hline \multirow{5}{*}{9} & 0.90 & $3 \mathrm{x}$ & 5.555 & 2.421 \\
& 0000 & $10^{8}$ & 556 & 611 \\
& $\mathrm{c}$ & $\mathrm{m} / \mathrm{s}$ & $\mathrm{Jam}$ & $\mathrm{Jam}$ \\
\hline \multirow{4}{*}{10} & 0.95 & $3 \mathrm{x}$ & 5.263 & 1.643 \\
& 0000 & $10^{8}$ & 158 & 421 \\
& $\mathrm{c}$ & $\mathrm{m} / \mathrm{s}$ & $\mathrm{Jam}$ & $\mathrm{Jam}$ \\
\hline
\end{tabular}

Dalam perhitungan manual kita ambil data kecepatan, kecepatan cahaya, dan waktu di bumi sama dengan data dalam aplikasi virtual. Hanya saja kita membuktikan hasil waktu diluar angkasa menggunakan persamaan rumus berikut.

$$
\begin{aligned}
t^{\prime} & =\frac{t^{\prime}}{\sqrt{1-\frac{v^{2}}{c^{2}}}} \\
t^{\prime} & =t \sqrt{1-\frac{v^{2}}{c^{2}}}
\end{aligned}
$$

Diketahui $: v=0.800000 c$

$$
t=6.250000 \mathrm{Jam}
$$

Ditanyakan $: t^{\prime}=\cdots$ ?

Jawab :

$$
\begin{gathered}
t^{\prime}=t \sqrt{1-\frac{v^{2}}{c^{2}}} \\
t^{\prime}=6.250000 \mathrm{Jam} \sqrt{1-\frac{(0.800000 c)^{2}}{c^{2}}}
\end{gathered}
$$




$$
\begin{gathered}
t^{\prime}=6.250000 \mathrm{Jam} \sqrt{1-\frac{0.64 c^{2}}{c^{2}}} \\
t^{\prime}=6.250000 \sqrt{1-0.64} \mathrm{Jam} \\
t^{\prime}=6.250000 \sqrt{0.36} \mathrm{Jam} \\
t^{\prime}=(6.250000)(0.6) \mathrm{Jam} \\
t^{\prime}=3.750000 \mathrm{Jam}
\end{gathered}
$$

\begin{tabular}{|c|c|c|c|c|}
\hline No & $\begin{array}{c}\text { Ke } \\
\text { cep } \\
\text { ata } \\
\text { n } \\
(v)\end{array}$ & $\begin{array}{c}\text { Kece } \\
\text { pata } \\
\text { n } \\
\text { Caha } \\
\text { ya (c) }\end{array}$ & $\begin{array}{c}\text { Wakt } \\
\text { u di } \\
\text { Bumi } \\
\text { (t) }\end{array}$ & $\begin{array}{c}\text { Wakt } \\
\text { u di } \\
\text { Luar } \\
\text { Angk } \\
\text { asa } \\
\left(t^{\prime}\right)\end{array}$ \\
\hline 1 & $\begin{array}{c}0.1 \\
000 \\
00 \mathrm{c}\end{array}$ & $\begin{array}{l}3 \mathrm{x} \\
10^{8} \\
\mathrm{~m} / \mathrm{s}\end{array}$ & $\begin{array}{c}50.00 \\
0000 \\
\text { Jam }\end{array}$ & $\begin{array}{c}49.750 \\
000 \\
\text { Jam }\end{array}$ \\
\hline 2 & $\begin{array}{c}0.2 \\
000 \\
00 \mathrm{c}\end{array}$ & $\begin{array}{l}3 \mathrm{x} \\
10^{8} \\
\mathrm{~m} / \mathrm{s}\end{array}$ & $\begin{array}{c}25.00 \\
0000 \\
\text { Jam }\end{array}$ & $\begin{array}{c}24.500 \\
000 \\
\text { Jam }\end{array}$ \\
\hline 3 & $\begin{array}{c}0.3 \\
000 \\
00 \mathrm{c}\end{array}$ & $\begin{array}{l}3 \mathrm{x} \\
10^{8} \\
\mathrm{~m} / \mathrm{s}\end{array}$ & $\begin{array}{c}16.66 \\
6667 \\
\text { Jam }\end{array}$ & $\begin{array}{c}15.833 \\
33365 \\
\text { Jam }\end{array}$ \\
\hline 4 & $\begin{array}{c}0.4 \\
000 \\
00 \mathrm{c}\end{array}$ & $\begin{array}{l}3 \mathrm{x} \\
10^{8} \\
\mathrm{~m} / \mathrm{s}\end{array}$ & $\begin{array}{c}12.50 \\
0000 \\
\text { Jam }\end{array}$ & $\begin{array}{c}11.456 \\
250 \\
\text { Jam }\end{array}$ \\
\hline 5 & $\begin{array}{c}0.5 \\
000 \\
00 \mathrm{c}\end{array}$ & $\begin{array}{l}3 \mathrm{x} \\
10^{8} \\
\mathrm{~m} / \mathrm{s}\end{array}$ & $\begin{array}{c}10.00 \\
000 \\
\text { Jam }\end{array}$ & $\begin{array}{c}8.6600 \\
00 \\
\text { Jam }\end{array}$ \\
\hline 6 & $\begin{array}{c}0.6 \\
000 \\
00 \mathrm{c}\end{array}$ & $\begin{array}{l}3 \mathrm{x} \\
10^{8} \\
\mathrm{~m} / \mathrm{s}\end{array}$ & $\begin{array}{c}8.333 \\
333 \\
\text { Jam }\end{array}$ & $\begin{array}{c}6.6666 \\
64 \\
\text { Jam }\end{array}$ \\
\hline 7 & $\begin{array}{c}0.7 \\
000 \\
00 \mathrm{c}\end{array}$ & $\begin{array}{l}3 \mathrm{x} \\
10^{8} \\
\mathrm{~m} / \mathrm{s}\end{array}$ & $\begin{array}{c}7.142 \\
857 \\
\text { Jam }\end{array}$ & $\begin{array}{c}5.2499 \\
9475 \\
\text { Jam }\end{array}$ \\
\hline 8 & $\begin{array}{c}0.8 \\
000 \\
00 \mathrm{c}\end{array}$ & $\begin{array}{l}3 \mathrm{x} \\
10^{8} \\
\mathrm{~m} / \mathrm{s}\end{array}$ & $\begin{array}{c}6.250 \\
000 \\
\text { Jam }\end{array}$ & $\begin{array}{c}3.7500 \\
00 \\
\text { Jam }\end{array}$ \\
\hline 9 & 0.9 & $3 x$ & 5.555 & 2.4222 \\
\hline
\end{tabular}

\begin{tabular}{|c|c|c|c|c|}
\hline & $\begin{array}{l}000 \\
00 \mathrm{c}\end{array}$ & $\begin{array}{l}10^{8} \\
\mathrm{~m} / \mathrm{s}\end{array}$ & $\begin{array}{l}556 \\
\text { Jam }\end{array}$ & $\begin{array}{c}22416 \\
\text { Jam }\end{array}$ \\
\hline \multirow{3}{*}{10} & 0.9 & $3 x$ & 5.263 & 1.6421 \\
\hline & 500 & $10^{8}$ & 158 & 08 \\
\hline & $00 \mathrm{c}$ & $\mathrm{m} / \mathrm{s}$ & Jam & Jam \\
\hline
\end{tabular}

Tabel 2. Data Nilai Dilatasi Waktu secara Perhitungan Manual
Berdasarkan hasil eksperimen, kita mendapatkan nilai dilatasi waktu secara perhitungan aplikasi virtual maupun perhitungan secara manual ekuivalen atau hampir sama.

Dalam eksperimen aplikasi virtual ini kita membuat pemisalan kerangka acuan. Kerangka acuan dalam percobaan ini yaitu pengamat $A$ dan pengamat $B$. Dimana pengamat A merupakan pengamat yang ikut bergerak dengan objek, sedangkan pengamat $\mathrm{B}$ diam tidak ikut bergerak dengan objek.

Misalkan pengamat A melakukan perjalanan keluar angkasa dengan menggunakan roket atau pengamat A ikut bergerak di dalam dengan objek, sedangkan pengamat $\mathrm{B}$ sebagai pengamat yang diam atau pengamat yang diluar tidak ikut bergerak dengan objek.

Pengamat A pergi keluar angkasa menggunakan roket dengan kecepatan tinggi hampir mendekati kecepatan cahaya, sehingga pengamat A akan merasakan waktu berjalan begitu lambat. Sedangkan menurut pengamat B yang diam melihat pengamat A di dalam roket dengan waktu yang lebih cepat dari pengamat sebelumnya. 
Sebagaimana telah kita ketahui bahwa kecepatan cahaya selalu bernilai konstan yaitu $3 \times 10^{8} \mathrm{~m} / \mathrm{s}$, maka ketika ada variabel lain yang mempengaruhi seperti variabel $v$ maka ia akan berusaha untuk mengkonstankan diri dengan mempengaruhi variabel lain yaitu $t$, dan ingat variabel kecepatan sifatnya kontinyu dan selalu melibatkan waktu $(t)$. Dimana $v=\frac{s}{t}$.

Oleh karena itu, bisa kita lihat dari data pengamatan dan hasil pengolahan data bahwa nilai dilatasi waktu berdasarkan percobaan aplikasi virtual maupun secara teoritis hasilnya sama yaitu ketika sebuah objek bergerak mendekati kecepatan cahaya maka objek tersebut mengalami penyusutan waktu atau waktu yang di tempuh berjalan lebih lambat daripada waktu bagi objek yang diam.

\section{SIMPULAN}

Berdasarkan hasil eksperimen dengan menggunakan aplikasi virtual yang telah kami lakukan, kami dapat menyimpulkan hasil eksperimen ini yaitu sebagai berikut.

1. Dengan menggunakan metode eksperimen virtual dapat meningkatkan pemahaman konsep mengenai dilatasi waktu karena dalam aplikasi virtual tersebut kita bisa langsung mendapatkan hasil dari dilatasi waktu secara matematis dan bisa dianalisis berdasarkan teori.
2. Nilai dari dilatasi waktu yang kami dapatkan secara perhitungan aplikasi virtual dengan perhitungan secara manual hasilnya ekuivalen yaitu hampir mendekati sama. Karena semakin kecepatan gerak suatu objek semakin besar, maka akan terjadi penyusutan waktu bagi objek yang bergerak dengan kecepatan tinggi.

\section{REFERENSI}

[1].https://id.wikipedia.org/wiki/Di latasi waktu

[2].https://www.walter-

fendt.de/html5/phen/timedilation_e n.htm

[3].Foster, Bob. 2015. Akselerasi Fisika Jilid 3 untuk SMA/MA Kelas XII. Penerbit Duta. [4].Beiser, Arthur. 1987. Konsep Fisika Modern (Terjemahan oleh The Houw Liong). Jakarta:Erlangga. 